\title{
Aortic stenosis in homozygous familial hypercholesterolaemia
}

\author{
L Rallidis, P Nihoyannopoulos, G R Thompson
}

Department of Medicine, Royal

Postgraduate Medical School, Hammersmith Hospital, London L Rallidis

P Nihoyannopoulos

MRC Lipoprotein

Team, Clinical

Sciences Centre, Royal

Postgraduate Medical

School, Hammersmith

Hospital, London

G R Thompson

Correspondence to:

Prof G R Thompson, MRC Lipoprotein Team, Clinical Sciences Centre, Royal Postgraduate Medical School, Hammersmith Hospital, Du Cane Road, London W12 0NN.

Accepted for publication 13 February 1996

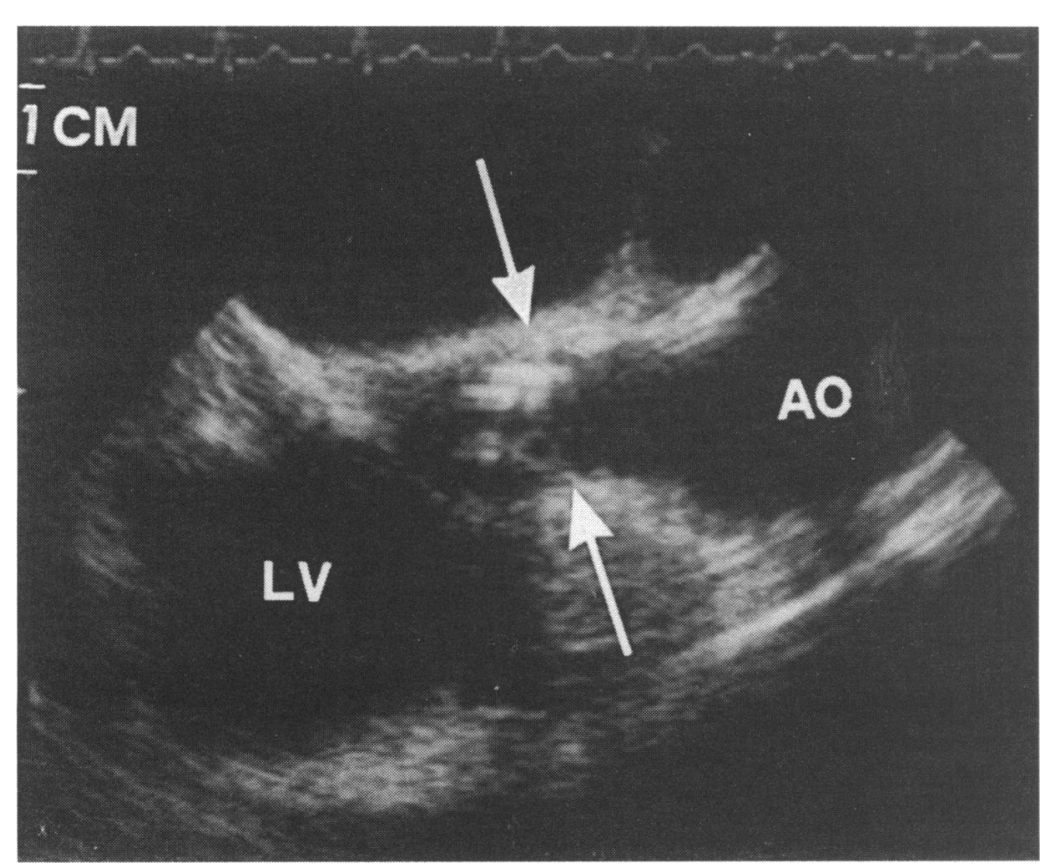

Transoesophageal echocardiogram showing the characteristic tapering of the aortic root and sinuses owing to atheromatous infiltration of the proximal ascending aorta (arrows). Also note the thickened aortic cusps adding to the overall pressure drop. The mean transaortic

gradient was $82 \mathrm{~mm} \mathrm{Hg}$.

Homozygous familial hypercholesterolaemia $(\mathrm{FH})$ is a rare disorder characterised by extreme hypercholesterolaemia, early appearance of cutaneous and tendon xanthomata, and premature cardiovascular involvement. Coronary artery disease (CAD) is common and is accompanied by aortic valve stenosis and atheromatous involvement of the aortic root. The surgical treatment of this condition carries a high risk even in skilled hands.

We report the case of a 25 year old Turkish woman who was referred with a presumptive diagnosis of homozygous $\mathrm{FH}$; her only symptom was effort dyspnoea. On examination she had bilateral hemi-arcus, planar xanthomata in the webs of the fingers, and Achilles tendon xanthomata. Auscultation revealed a loud $(4 / 6)$ ejection systolic murmur at the aortic area with a loud aortic closure sound.

She was taking daily doses of simvastatin $(20 \mathrm{mg})$ and cholestyramine $(12 \mathrm{~g})$. Serum total cholesterol was $14.9 \mathrm{mmol} / \mathrm{l}$, low density lipoprotein cholesterol (LDL) $13.7 \mathrm{mmol} / 1$, triglyceride $0.94 \mathrm{mmol} / \mathrm{l}$, high density lipoprotein cholesterol $0.88 \mathrm{mmol} / \mathrm{l}$, and lipo- protein (a) $23 \mathrm{mg} / \mathrm{dl}$. An echocardiogram showed severe aortic stenosis with a mean gradient of $53 \mathrm{~mm} \mathrm{Hg}$. Eight months later she developed dizziness on exertion. Exercise echocardiography (modified Bruce) showed $3 \mathrm{~mm}$ down-sloping ST depression in inferolateral leads after 3 minutes, with extensive inferior akinesis. Repeat echocardiography with transoesophageal imaging showed that the diameter of the ascending aorta tapered down from $27 \mathrm{~mm}$ to $15 \mathrm{~mm}$ at the root (figure). The aortic sinuses were markedly thickened and echogenic, implying extensive atheromatous deposition. The aortic valve was also markedly thickened, mainly at the tips, but remained mobile. Cardiac catheterisation showed moderate stenosis of the left anterior descending coronary artery (LAD) and right ostial occlusion, a transaortic valvar gradient of $110 \mathrm{~mm} \mathrm{Hg}$, and funnelling of the aortic root with partial obliteration of the sinuses of Valsalva.

In view of her progressive symptoms and the severe aortic stenosis and CAD she underwent urgent cardiac surgery. The aortic valve, the cusps of which were thickened and had yellow deposits, was excised, the aortic root was enlarged with a pericardial patch and a 19 mm St Jude prosthesis was inserted. The left internal mammary artery was grafted to the $\mathrm{LAD}$ and the right internal mammary artery to the right coronary artery. Histological examination of the aortic valve showed focal deposition of cholesterol and calcium, together with fibrosis and chronic inflammatory changes.

Aortic root disease is the commonest cardiac manifestation of homozygous $\mathrm{FH}$ and by puberty all patients have some degree of atheromatous involvement of the ascending aorta. This results in ostial stenosis as atheroma in the sinuses of Valsalva encroaches on the coronary ostia, with a potentially fatal outcome. Although the supravalvar deposition of atheroma in itself is seldom haemodynamically important, it restricts full excursion of the aortic leaflets, creating secondary valvar aortic stenosis characterised by an ejection systolic murmur without a click and with a loud aortic closure sound. ${ }^{1}$ The aortic valve itself is also infiltrated with atheroma but its mobility is relatively well preserved. The simplest way to monitor the severity of aortic stenosis is by Doppler echocardiography. ${ }^{2}$ 
Outcome in FH homozygotes undergoing aortic root reconstruction, insertion of prosthetic valve, and coronary artery bypass grafting at Hammersmith and St Mary's Hospitals, London

\begin{tabular}{|c|c|c|c|c|}
\hline Case no & Sex & Age at operation & Operative procedure & Outcome \\
\hline 1 & $\mathbf{F}$ & 28 & Björk-Shiley valve, ARR & Alive \\
\hline 2 & $\mathbf{M}$ & 19 & $\begin{array}{l}\text { Björk-Shiley valve, Konno } \\
\text { operation, }{ }^{4} 3 \text { grafts }\end{array}$ & Died \\
\hline 3 & $\mathbf{M}$ & 31 & $\begin{array}{l}\text { Duromedics valve, ARR } \\
\text { (pericardial patch), } 3 \text { grafts }\end{array}$ & Died \\
\hline 4 & $\mathrm{~F}$ & 14 & $\begin{array}{l}\text { Björk-Shiley valve, ARR } \\
\text { (pericardial patch), } 1 \text { graft }\end{array}$ & Alive \\
\hline 5 & $\mathbf{F}$ & 26 & $\begin{array}{l}\text { St Jude valve, ARR } \\
\text { (pericardial patch), } 2 \text { grafts }\end{array}$ & Alive \\
\hline
\end{tabular}

$\mathrm{ARR}$, aortic root reconstruction; CABG, coronary artery bypass graft.

The management of homozygous FH presents a major therapeutic challenge. The commonest form of lipid-lowering treatment nowadays is $L D L$ apheresis every $1-2$ weeks, usually combined with statins. This slows the rate of progression of aortocoronary atherosclerosis but can worsen the aortic stenosis because the removal of cholesterol may paradoxically accelerate valvar fibrosis.
Despite the improved prognosis resulting from medical treatment ${ }^{3}$ most patients eventually require surgery. The combination of severe aortic stenosis and CAD necessitates aortic valve replacement and coronary artery bypass grafting. Reconstruction of the aortic root is the main operative risk and carries a high mortality (table). In our patient (case 5) this procedure was successful, but two of four similarly treated patients died.

We are grateful to Professor C Oakley, Mr P Smith, and Dr D Parums for their help and advice, and to Professor A Winde for referring the patient.

1 Allen JM, Thompson GR, Myant NB, Steiner R, Oakley CM. Cardiovascular complications of homozygous familial hypercholesterolaemia. Br Heart f 1980;44:361-8

2 Ribeiro P, Shapiro LM, Gonzalez A, Thompson GR, Oakley $\mathrm{CM}$. Cross sectional echocardiographic assessment of the aortic root and coronary ostial stenosis in familial hypercholesterolaemia. Br Heart $\mathcal{F}$ 1983;50:432-7.

3 Thompson GR, Miller JP, Breslow JL. Improved survival of patients with homozygous familial hypercholesterolaem treated by plasma exchange. Br Med F 1985;291:1671-3.

4 Konno S, Imai $Y$, Iida $Y$, Nakajima $M$, Tatsuno $K$. A new method for prosthetic valve replacement in congenital aortic stenosis associated with hypoplasia of the aortic valve ring. F Thorac Cardiovasc Surg 1975;70:909-17. 